\title{
PENGARUH PERAWATAN METODE KANGURU TERHADAP RESPON FISIOLOGIS BAYI PREMATUR DAN KEPERCAYAAN DIRI IBU DALAM MERAWAT BAYI
}

\author{
Nurhayati Wahyu Trianingsih \\ AKBID Borneo Medistra Balikpapan \\ Email:wahyu@akbidborneomedistra.ac.id \\ Istiqomah \\ AKBID Borneo Medistra Balikpapan \\ Email: isti@akbidborneomedistra.ac.id \\ Dewi Ari Sasanti \\ AKBID Borneo Medistra Balikpapan \\ Email: dewi@akbidborneomedistra.ac.id
}

\begin{abstract}
Abstrak
Penelitian bertujuan untuk mengidentifikasi respon fisiologis bayi prematur dan kepercayaan diri ibu selama perawatan di dua rumah sakit di Balikpapan. Jenis penelitian adalah quasi eksperimental dengan desain prets posttest one group design. Pengambilan sampel dengan metode carapurposive sampling dengan sampel 10 responden. Instrumen penelitian adalah kuesioner yaitu kuesioner kepercaya diri pada ibu, Maternal Confidence Questionaire (MCQ) sebagai alih bahasa untuk mengukur variabel kepercayaan diri ibu dalam merawat bayi. Hasil Penelitian memperlihatkan perbedaan bermakna pada frekuensi denyut jantung, suhu tubuh, saturasi oksigen bayi prematur serta kepercayaan diri ibu dalam merawat bayi sebelum dan sesudah dilakukan perawatan. Terdapat perbedaan yang signifikan antara kepercayaan diri ibu dalam merawat bayi prematur sebelum dan sesudah menggunakan PMK. Terdapat perbedaan yang bermakna suhu tubuh bayi prematur frekuensi denyut jantung dan saturasi oksigen sebelum dan sesudah dilakukan PMK. PMK yang selama ini dilakukan di ruang Perinatalogi Dr. R. Hardjanto dan RSUD Beriman, bisa dijadikan sebagai tindakan yang rutin dan semua perawat anak yang dinas di ruangan Perinatalogi diberikan pelatihan PMK. Ruang Perinatalogi sebaiknya memiliki ruangan khusus PMK dan menyediakan rumah singgah bagi ibu, agar dapat mengunjungi bayinya setiap hari khususnya untuk PMK.
\end{abstract}

Kata Kunci :bayi prematur, fisiologis bayi, kepercayaan diri ibu dalam merawat bayi

\section{Abstract}

The study aims at identifying the physiological response premature infants and confidence of pregnant mothers during treatment in two hospitals in balikpapan.. This type of research is quasi-experimental with group pre and post-test. Sampling by carapurposive sampling with a sample of 10 respondents. Research instruments 
are questionnaires, namely the mother's self-confidence questionnaire, language transfer from the Maternal Confidence Questionaire (MCQ), used to measure the variables of mother's self-confidence in caring for babies. Research Results Shows that there are significant differences in body temperature, heart rate, oxygen saturation in premature infants, and maternal confidence in caring for babies before and after care. There was a significant difference between maternal confidence in treating premature babies before and after PMK. There were significant differences in body temperature of heart rate preterm infants and oxygen saturation before and after FMD. FMD which has been carried out in the space of the Perinatalogy Dr. R. Hardjanto and Beriman Hospital can be used as routine actions and all official child nurses in the Perinatalogy room are given PMK training. The Perinatology Room should have a special room for PMK and provide shelters for mothers, so they can visit their babies every day especially for $P M K$

Keywords: premature babies, baby physiology, mother's confidence in caring for babies

\section{PENDAHULUAN}

Indonesia negara di Asia yang memiliki tingkat kematian bayi tertinggi di ASEAN. Survey Demografi Kesehatan Indonesia (2007) menunjukkan bahwa sekitar 401 bayi baru lahir di Indonesia meninggal sebelum berumur satu tahun perharinya, 15 bayi barulahir diperkirakan meninggal setiap jamnya dan 15 bayi baru lahir meninggal setiap 6 menit. Sebesar 32,4\% kematian bayi berusia 0- 6 hari diIndonesia disebabkan oleh prematuritas (Sulani, 2009). Lahir dengan berat yang kurang dapat menimbulkan berbagai resiko seperti infeksi, kesulitan bernafas, hipotermi dan reflek menyusu yang kurang atau dapat terjadi gangguan nutrisi (Elizabeth et.al, 2013).

Perawatan yang dilakukan oleh ibu secara langsung dapat menstabilkan suhu tubuh bayi, detakan jantung, respirasi, tingkah laku bayi kurang menangis dan sering menyusui, penggunaan kalori berkurang, kenaikan berat badan bayi, waktu tidur bayi lebih lama serta hubungan kedekatan bayi dengan ibu lebih baik (Perinasia, 2008). Keberhasilan pelaksanaan metode ini sangat dipengaruhi oleh dukungan ibu dalam melaksanakan PMK, ibu yang melaksanakan PMK dengan baik akan berdampak pada peningkatan suhu tubuh bayi dan terhindar dari kejadian hipotermi (Nurrohman, 2008). Boy (2007) mengemukakan bahwa metode PMK sangat membantu dalam meningkatkan suhu tubuh bayi dan menghindari terjadinya hipotermi. Pelekatan bayi BBLR pada ibu selama 24 jam akan membantu suhu tubuh bayi tetap stabilk 
dikarenakan ibu mengkondisikan tempat yang sama dengan kondisi pada rahim ibu akan tetapi tidak sedikit ibu-ibu post partum yang belum melaksanakan PMK ini dengan baik sehingga menyebabkan bayi mengalami hipotermi. Merawatan bayi dengan menggunakan inkubator, dapat mengakibatkan terjadinya pemisahan bayi dengan ibunya. Keadaan ini, menjadi salah satu penyebab kurang percaya diri ibu dalam merawat bayinya.

Tujuan penelitian ini untuk mengidentifikasi pengaruh perawatan metode kanguru terhadap fungsi fisiologis dan kepercayaan diri ibu dalam merawat bayi.

\section{METODOLOGI PENELITIAN}

Penelitian ini merupakan penelitan quasi experimental dengan desain yang digunakan adalah pretes posttest one group design. Sampel sebanya 10 responden yang diperoleh dengan menggunakan metode carapurposive sampling. Instrumen penelitian yang digunakan adalah kuisoner kepercayaan diri ibu, alih bahasa oleh Maternal Confidence Questionaire (MCQ) untuk mengukur variabel kepercayaan diri ibu pada saat merawat bayi. Perawatan Metode Kangguru dilakukan selama 3 hari pada setiap bayi. Peneliti melakukan penyuluhan kesehatan terkait metode kangguru serta meminta persetujuan responden untuk terlibat penelitian. Selanjutnya peneliti memeriksa fungsi fisiologis bayi, yang terdiri dari suhu tubuh, frekuensi denyut jantung, saturasi oksigen. Selain itu, peneliti membagikan kuesioner kepercayaan diri ibu dalam merawat bayi sebelum menerapkan PMK.

Pelaksanaan PMK dalam 1 (satu) jam pada hari pertama. Pemeriksaan fungsi fisiologis dilakukan setelah PMK. Pemeriksaan sebelum dilakukan PMK, dilakukan pada bayi sebelum dilekatkan pada dada ibu, sedangkan pemeriksaan sesudah PMK, dilakukan setelah bayi dalam posisi kangguru selama 1 jam dan diperiksa kembali, frekuensi denyut jantung, suhu tubuh, dan saturasi oksigen ketika bayi pada saat bayi posisi kangguru. Hari kedua, pemeriksaan fisiologis bayi dilakukan sebelum ibu menerapkan PMK, kemudian sesudah ibu melakukan PMK selama 1 jam. Hari ketiga, pemeriksaan fungsi fisiologis dilakukan sebelum dan setelah PMK. Selanjutnya, ibu mengisi kuesioner setelah PMK dan peneliti mengucapkan terimakasih kepada responden.

Data penelitian dianalisis dengan program spss, kemudian dianalisis dengan menggunakan uji univariat, dan bivariat. Uji univariat dilakukan untuk melihat variabel 
karakteristik responden bayi prematur baik usia, jenis kelamin dan berat badan lahir serta melihat karakteristik ibu baik usia, masa gestasi dan paritas. Uji bivariat yang digunakan adalah Wilcoxon test.

\section{HASIL DAN PEMBAHASAN}

Tabel 1. Distribusi Responden Berdasarkan Jenis Kelamin Bayi di RST dan RSU di Balikpapan Oktober - November 2018

\begin{tabular}{|c|c|c|c|c|c|c|}
\hline \multirow[b]{2}{*}{ Bayi Lahir } & \multicolumn{2}{|c|}{ RST } & \multicolumn{2}{|l|}{ RSU } & \multicolumn{2}{|c|}{ TOTAL } \\
\hline & $\mathrm{N}$ & $\%$ & $\mathrm{~N}$ & $\%$ & $\mathrm{~N}$ & $\%$ \\
\hline Laki-Laki & 2 & $40 \%$ & 4 & 80 & 6 & $60 \%$ \\
\hline Perempuan & 3 & $60 \%$ & 1 & $20 \%$ & 4 & $40 \%$ \\
\hline
\end{tabular}

Tabel diatas memperlihatkan bahwa jenis kelamin laki-laki bayi prematur yang dirawat di RST sebanyak 2 orang, sedangkan jenis kelamin laki-laki yang dirawat di RSU sebanyak 4 orang. Untuk jenis kelamin perempuan sebanyak 3 orang di RST dan sebanya 1 orang di RSU.

Tabel 2. Distribusi Responden Berdasarkan Umur (hari) dan Berat Badan Lahir (gram) Bayi di RST dan RSU di Balikpapan Oktober-November 2018

\begin{tabular}{lllll}
\hline RST & Mean & Median & SD & Min-Mak \\
\hline Umur Bayi & 1.40 & 1.00 & 0.548 & $1-2$ \\
Berat Badan Lahir & 2246 & 2250 & 105.26 & $2100-2380$ \\
RSU & Mean & Median & SD & Min-Mak \\
Umur Bayi & 1.40 & 1.00 & .548 & $1-2$ \\
Berat Badan Lahir & 2230 & 2350 & 99.97 & $2200-2400$ \\
Total & 2.40 & 2.00 & 2.00 & $1-7$ \\
& 2280 & 2300 & 99.97 & $2100-2400$ \\
\hline
\end{tabular}

Berdasarkan table diatas, rerata berat bayi prematur di RST adalah 2246 gram dan di RSU adalah 2230 gram. Rerata berat badan lahir bayi prematur secara keseluruhan yaitu 2280 gram.

Tabel 3. Distribusi Responden Berdasarkan Umur (tahun), Masa Gestasi (bulan), dan Paritas Ibu di RST dan RSU di Balikpapan Oktober - November 2018

\begin{tabular}{lccc}
\hline RST & Mean & Median & SD \\
Usia Ibu & 34.0 & 40 & 8.124 \\
\hline Masa Gestasi & 33.0 & 33.00 & 1.000 \\
Paritas & 3.00 & 3.00 & 1.581 \\
RSU & & & \\
Usia Ibu & 36.8 & 40 & 5.167 \\
Masa Gestasi & 34.8 & 36.00 & 2.950 \\
Paritas & 2.40 & 2.00 & .548
\end{tabular}




\section{Total}

Usia Ibu

Tabel 3. Menunjukkan rerata usia ibu yang memiliki bayi prematur di RST di Balikpapan adalah 34 tahun dan rerata usia ibu di RSU adalah 36,8 tahun. Rerata usia ibu secara keseluruhan yaitu 35,40 tahun. Untuk melihat pengaruh PMK terhadap suhu tubuh, frekuensi denyut jantung, saturasi oksigen bayi prematur dan kepercayaan diri ibu dalam merawat bayi sebelum dan sesudah PMK digunakan uji wilcoxon. Adapun gambaran fungsi fisiologis bayi prematur sebelum dan sesudah PMK adalah sebagai berikut:

Tabel 4. Distribusi Rata-rata Suhu Tubuh Bayi Prematur Sebelum dan Sesudah Dilakukan PMK di RST dan RSUdi Balikpapan Oktober - November 2018

\begin{tabular}{cccc}
\hline Hari & Variabel & Mean & P Value \\
\hline I & Suhu Tubuh & & \\
& Sebelum & 36.2 & 0.000 \\
Sesudah & 36.6 & 0,000 \\
II & $\begin{array}{l}\text { Suhu Tubuh } \\
\text { Sebelum }\end{array}$ & 36.71 & 0,000 \\
& Sesudah & 36.71 & 0,000 \\
& Suhu Tubuh & 36.91 & 0,000 \\
SII & Sebelum & 36.71 & 0,000 \\
\hline
\end{tabular}

Tabel 4 diatas memperlihatkan perbedaan yang signifikan terhadap suhu tubuh bayi prematur sebelum dan setelah PMK baik pada hari I, II, dan III. Terlihat suhu tubuh bayi prematur berada dalam batas normal.

Tabel 5. Denyut Jantung Bayi Prematur Sebelum dan Sesudah Dilakukan PMK di RSUD dan RST di Balikpapan Oktober dan November 2018

\begin{tabular}{clrc}
\hline Hari & Variabel & Mean & P Value \\
\hline I & Frekuensi Denyut Jantung & \\
& Sebelum & 129.40 & 0.000 \\
& Setelah & 151.90 & \\
& Frekuensi Denyut Jantung & & \\
II & Sebelum & 137.20 & 0.000 \\
& Setelah & 145.00 & \\
& Frekuensi Denyut Jantung & & \\
& Sebelum & 138.40 & 0.000 \\
& Setelah & 146.80 & \\
\hline
\end{tabular}


Tabel diatas memperlihatkan bahwa tidak ada perbedaan frekuensi denyut jantung bayi prematur sebelum dan setelah PMK diRSUD dan RST di Balikpapan, pada hari I $(p=0.065)$, hari II $(p=0.082)$, dan hari III $(p=0.191)$

Tabel 6. Distribusi Rata-rata Saturasi Oksigen Bayi Prematur Sebelum dan Sesudah Dilakukan PMK di RSUD dan RST di Balikpapan Oktober dan November 2018

\begin{tabular}{cllc}
\hline Hari & Variabel & Mean & P Value \\
\hline I & Saturasi Oksigen & & \\
& Sebelum & 91.80 & 0.000 \\
& Setelah & 96.00 & \\
SI & Saturasi Oksigen & 94.60 & 0.000 \\
& Sebelum & 97.30 & \\
& Setelah & & \\
& Saturasi Oksigen & & \\
& Sebelum & 93.10 & 0.000 \\
& Setelah & 96.40 & \\
\hline
\end{tabular}

Tabel 6. menunjukkan tidak terdapat perbedaan yang bermakna terhadap rata- rata saturasi oksigen bayi prematur sebelum dan sesudah PMK diRSUD dan RST di Balikpapan Oktober dan November 2018, pada hari I ( $p=0.000)$, hari II ( $p=0.000)$, dan hari III $(\mathrm{p}=0.000)$.

Tabel 7. Distribusi Pengaruh PMK Terhadap Rata-rata Keseluruhan Suhu Tubuh, Frekuensi Denyut Jantung, Saturasi Oksigen pada Bayi dan Kepercayaan Diri Ibu Dalam Merawat Bayi di RSUD dan RST di Balikpapan

Oktober dan November 2018

\begin{tabular}{lccc}
\hline Variabel & Mean & SD & P Value \\
\hline Suhu Tubuh & & & \\
Sebelum & 36.527 & .2303 & 0.000 \\
Setelah & 36.877 & .1591 & \\
& & & \\
Denyut Jantung & & & \\
Sebelum & 135.00 & 15.324 & 0.000 \\
Setelah & 147.90 & 8.600 & \\
Saturasi Oksigen & & & \\
Sebelum & 93.17 & 2.679 & 0.000 \\
Setelah & 96.57 & 2.192 & \\
Kepercayaan Diri & & & \\
Sebelum & 61.60 & 4.658 & 0.000 \\
Setelah & 64.07 & 4.727 & \\
\hline
\end{tabular}

Tabel 7. menunjukkan bahwa rata-rata keseluruhan suhu tubuh bayi sebelum dilakukan PMK di RSUD dan RST Balikpapan adalah $36,7^{\circ} \mathrm{C}$ dan sesudah dilakukan PMK adalah $36,9^{\circ} \mathrm{C}$. Analisis lebih lanjut menunjukkan terdapat perbedaan yang bermakna antara rata-rata suhu tubuh bayi sebelum dan sesudah dilakukan PMK, 
dengan kata lain dapat dilihat bahwa secara signifikan PMK dapat menaikkan suhu tubuh bayi prematur $\quad(\mathrm{P}$ value $=0,000, \alpha=0,05)$.

\section{PEMBAHASAN}

Penelitian ini menggunakan subyek bayi prematur yang dirawat di ruang Rumah Sakit Dr. R. Hardjanto dan RSUD Beriman di Balikpapan pada bulan Oktober sampai November 2018. Jumlah responden pada penelitian ini terdiri dari 5 bayi prematur dan 5 ibu yang dirawat di Rumah Sakit Dr. R. Hardjanto dan RSUD Beriman di Balikpapan di Balikpapan. Responden pada penelitian ini rata-rata berusia 2 hari. Hasil penelitian ini berbeda dengan penelitian yang dilakukan oleh dengan PMK pada bayi prematur di negara Jepang. Rata-rata umur bayi pada saat penelitian dari 16 responden adalah 60 hari, dengan rata- rata masa gestasi 28 minggu (Nur, et al., 2016). Jadi pada saat dilakukan penelitian PMK, bayi sudah dirawat sekitar dua bulan di dalam inkubator. Rata-rata berat badan lahir bayi prematur di Dr. R. Hardjanto dan RSUD Beriman di Balikpapan adalah 2280 gram. Hasil penelitian ini berbeda dengan penelitian Feldman, et al. (2002), bahwa rata- rata berat badan lahir bayi prematur yang ditelitinya dari 146 bayi prematur adalah 1270 gram. Penelitian ini mempunyai rata-rata berat badan lahir bayi lebih rendah, dibandingkan dengan rata-rata berat badan lahir bayi prematur yang didapatkan oleh peneliti.

Usia ibu yang memiliki bayi prematur di Dr. R. Hardjanto dan RSUD Beriman di Balikpapan adalah sekitar 34 tahun. Usia yang paling muda adalah 22 tahun dan yang paling tua adalah 42 tahun. Hasil ini memperkuat bahwa faktor resiko terjadinya kelahiran bayi prematur diantaranya adalah faktor usia ibu. Wanita yang berusia lebih dari 35 tahun akan meningkatkan resiko mengalami persalinan prematur, $64 \%$ peningkatan kejadian persalinan prematur pada wanita Itali yang berusia 35 tahun atau lebih, terutama terjadi pada kehamilan pertama (Astolfi \& Zonda dalam Wijayanegara, et al., 2009).

Rerata masa gestasi ibu yang melahirkan bayi prematur dan dirawat di Dr. R. Hardjanto dan RSUD Berimanadalah 33 minggu. Hasil penelitian ini sejalan dengan penelitian lain yang menyebutkan rata-rata masa gestasi ibu yang mempunyai bayi prematur adalah 32 minggu. Jumlah responden pada penelitian ini adalah 25 bayi prematur (Wilhem, 2005). Rerata paritas ibu adalah 3 anak. Beberapa penelitian menyebutkan bahwa rerata paritas ibu yang mempunyai bayi prematur adalah 2 anak. 
Responden pada penelitian tersebut berjumlah sebanyak 25 orang ibu (Wilhem, 2005). Ketidaksesuaian antara paritas ibu dan kejadian kelahiran bayi prematur dapat disebabkan oleh faktor lain yang lebih dominan, sehingga menyebabkan bayi tersebut lahir prematur, seperti antara lain disebabkan oleh riwayat ibu yang pernah melahirkan prematur sebelumnya, penyakit yang diderita ibu dan keadaan kehamilan.

\section{SIMPULAN}

Terdapat perbedaan yang bermakna antara kepercayaan diri ibu dalam merawat bayi prematur sebelum dan sesudah dilakukanPMK. Terdapat perbedaan yang bermakna suhu tubuh bayi prematur sebelum dan sesudah dilakukan PMK.

\section{UCAPAN TERIMAKSIH}

1. Kepada DRPM Ristekdikti yang telah membiayai penelitian dosen pemula

2. Kepada PPM Akademi Kebidanan Borneo Medistra Balikpapan

\section{DAFTAR PUSTAKA}

Endyarni, B., Roeslani, D.R., Rohsiswatmo, R., \& Soedjadmiko. 2009. Mothers' response on kangaroo mother care intervension for preterm infants. Pediatrica Indonesia, 49(4), 224-8.

Elizabeth NL, Christopher OG, Patrick K. (2013). Determining an anthropometric surrogate measure for identifying low birth weight babies in Uganda: a hospitalbased cross sectional study. BMC Pediatric. 13-54

Jeffries, P. R. (Ed.). (2012). Simulation in nursing education: From conceptualization to evaluation (2nd ed.). New York, NY: National League for Nursing.

Maryuni, A. 2013. Buku Saku Asuhan Bayi Dengan Berat Badan Lahir Rendah. Jakarta: Trans Info Media.

Maryunani, A dan Nurhayati. (2009). Asuhan Kegawatdaruratan Dan Penyulit Pada Neonatus. CV. Trans Info media, Jakarta

Meadow S.R dan Newell S.J., (2005). Lecture Notes: Pediatrika. Edisi 7. Jakarta: Erlangga. pp. 80-1

Mitayani. (2010). Mengenal Bayi Baru Lahir dan Penatalaksanaannya.Padang : Praninta Offset.

Mohctar, P. (2004). Obsetri dan gynecologi. Edisi 5. Jakarta: EGC

Nur Sri Atik, Sri Achadi Nugraheni, Kusyogo Cahyo, (2016). Analisis Implementasi Program Perawatan Metode Kanguru (PMK) Dan Partisipasi Pasien Pada Pelayanan Kesehatan Bayi Berat Lahir Rendah (BBLR) (Studi pada Pasien di Rumah Sakit Mardi Rahayu Kudus). Jurnal. Vol.4, No. 2 
Nurrohman, (2008). Keperawatan Bayi BBLR http//www.wordpress.com, diakses: $10 / 7 / 2017$

Pantiawati, I. (2010). Bayi dengan Berat Badan Lahir Rendah. Yogyakarta: Nuha Medika

Perinasia. (2008). Perawatan bayi berat lahir rendah dengan metode kanguru. Jakarta: Perinasia

Prawitasari,A\& Cahyo,I. (2010). BBLR Berat Badan Lahir Rendah. Jakarta: Nuha Medika.

Proverawati Atikah, \& Ismawati Cahyo, S. (2010). BBLR : Berat Badan Lahir Rendah. Yogyakarta: Nuha Medika.

Rukmono P. (2013). Neonatologi praktis. Bandar Lampung: AURA.

Ruth, F., Eidelman, I A., Sirota, L., \& Weller, A. (2002). Comparison of Skin-to-skin (kangaroo) and traditional care: Parenting outcomes and preterm infant development. Pediatrics, 110, 16-26

Sudarti. (2013). Asuhan Neonatus Risiko Tinggi dan Kegawatan. Jakarta. Buku Kedokteran : EGC.

Sulani F. (2009). Masalah Pertumbuhan Janin Terhadap (PJT) dan Bayi Berat Lahir Rendah (BBLR) di Indonesia Banjarmasin : Kongres Nasional X Perinasia.

Wijayanegara, H. et al. (2009). Prematuritas Bandung. Penerbit Refika Aditama

Williams, et al. (1987) transition to motherhood: A longitudinal study. Infant Metal Healt Journal, 8(4) 251-256 dalam Daxtator, L.A. 2003 Maternal coufidence aconfaration between mother of term and preterm infants by feading methods thesis. Canada : Queen's Univercity http:www.proquest.umi.com diperoleh tanggal 11 Juni 2017 